\title{
EL SUFRAGIO DE LAS PERSONAS PRIVADAS DE LIBERTAD. UN ANÁLISIS A PARTIR DE LA SENTENCIA ROL No 87743-16 DE LA CORTE SUPREMA Y SUS ANTECEDENTES
}

\author{
THE SUFFRAGE OF PRISONERS. AN ANALYSIS FROM THE SUPREME \\ COURT'S JUDGMENT ROL NO 87743-16 AND ITS BACKGROUND
}

\section{Pablo Marshall* \\ Diego Rochow**}

\begin{abstract}
RESUMEN: El presente artículo tiene por objeto analizar la sentencia de la Corte Suprema que ordenó la adopción de todas las medidas necesarias para que las personas privadas de libertad habilitadas puedan ejercer su derecho a sufragio. Se exponen los antecedentes de la sentencia, el proceso que culminó con su dictación, y el contenido del fallo. Asimismo, se presentan algunas reflexiones que valoran positivamente ciertos aspectos de la decisión de la Corte que consolida su preocupación por los privados de libertad.
\end{abstract}

Palabras clave: Privados de libertad, derecho a sufragio, igualdad, elecciones

ABSTRACT: This article analyses the Chilean Supreme Court's judgment that ordered the adoption of all necessary measures to allow prisoners be able to exercise their right to vote. The antecedents of the judgment, the process, and the content of the judgment are exposed. Likewise, some reflections are presented that assess positively certain aspects of the Court's decision that consolidates its concern for those deprived of their liberty.

Keywords: Prisoners, right to vote, equality, elections

\section{INTRODUCCIÓN}

Una de las características de la población penal chilena es que se encuentra marginalizada políticamente. Las prisiones en nuestro país son espacios en que los internos no cuentan con medios para manifestar sus opiniones, expresar sus preocupaciones o promover sus intereses. De esta manera, no existe un canal a través del cual sus peticiones puedan ser escuchadas tanto por las autoridades políticas como por la ciudadanía. Demandas referidas a la mejora en sus condiciones de vida, la defensa y tutela de sus derechos por parte

\footnotetext{
* Doctor por la Universidad de Glasgow. Profesor de la Facultad de Ciencias Jurídicas y Sociales de la Universidad Austral de Chile; Dirección postal: Campus Isla Teja s/n, Valdivia. Dirección electrónica: pmarshall@ uach.cl.

** Abogado. Licenciado en Ciencias Jurídicas y Sociales por la Universidad de Chile. Ayudante del Departamento de Ciencias Penales de la Facultad de Derecho de la Universidad de Chile. Dirección postal: Avenida Santa María 0200, Providencia, Santiago. Dirección electrónica: diegobastian.rs@gmail.com.
} 
de organismos especializados e independientes, o la posibilidad de ejercer en la práctica sus derechos a la libre asociación, expresión y sufragio, se encuentran, así, silenciadas ${ }^{1}$.

Esta falta de canales de participación y expresión no es, sin embargo, un antojo de las autoridades de turno. La propia Constitución Política consagra lo que parte de la literatura ha denominado como una verdadera "muerte cívica" de los privados y las privadas de libertad ${ }^{2}$. Mientras el artículo $16 \mathrm{n}^{\circ} 2$ del texto constitucional señala que el derecho a sufragio se suspende si una persona es acusada por delito que merezca pena aflictiva o que la ley califique como conducta terrorista, el artículo 17 no 2 establece que las personas condenadas a cumplir una pena aflictiva pierden la ciudadanía. Si la noción de ciudadanía ha sido reivindicada como el elemento central de la política democrática de nuestro siglo ${ }^{3}$, el significado de la expulsión de quienes son condenados en la comunidad política de ciudadanos libres e iguales no puede pasar inadvertido. Más aún al considerar que dicha operación se encuentra constitucionalmente establecida. Estas disposiciones parecen tener un contenido jurídico y político que puede irradiar simbólicamente al resto del ordenamiento jurídico, transformando a quienes son sancionados penalmente en sujetos que no pertenecen, física, social y políticamente a nuestra comunidad ${ }^{4}$.

Parte de ese efecto de irradiación se manifiesta en que las autoridades, mediante una práctica contraria a los más básicos principios del Estado de Derecho, han fallado en establecer un mecanismo electoral que permita sufragar a todos aquellos sujetos privados de libertad que no han sido, además, privados ni legal ni constitucionalmente de su derecho a sufragio. Como consecuencia, los imputados sujetos a prisión preventiva se encuentran privados fácticamente de la posibilidad de sufragar, pese a que ninguna norma lo prescribe de ese modo. Lo mismo ocurre con quienes cumplen penas privativas de libertad inferiores a tres años y un días.

Esta última situación, sin embargo, pareciera empezar a tomar un nuevo rumbo producto de un fallo reciente de la Corte Suprema. En este, la Corte reconoció que los sujetos privados de libertad que no han sido condenados a una pena aflictiva son titulares del derecho a sufragio y que impedir su ejercicio implica una afectación de sus derechos fundamentales de la que las instituciones involucradas, el Servicio Electoral (Servel, en adelante) y Gendarmería de Chile, serían directamente responsables. Esta sentencia puede constituir un golpe de timón en la trayectoria tanto de la protección de los derechos electorales como de los derechos de las personas privadas de libertad. El presente comentario tiene por objeto analizar la sentencia de la Corte Suprema que ordenó la adopción de todas las medidas necesarias para que las personas privadas de libertad habilitadas puedan ejercer su derecho

\footnotetext{
1 Para analizar las reflexiones en torno a esta idea en el país, véase ArRiAgADA y Rochow (2015) p. 205, e Instituto Nacional de Derechos Humanos (2012) p. 146. En cuanto a los problemas que genera la falta de participación política de los internos en la posición institucional de la prisión en una democracia, véase HaRCOURT (2014).

$2 \mathrm{Al}$ respecto, véase GUZmán DÁlbora (2008) pp. 273-302. Sobre las consecuencias teóricas de la aplicación de la pérdida de la ciudadanía, véase MaÑalich (2011a) y MARSHALl (2013).

3 Véase, por ejemplo, Balibar (2004) y TAMBAKaKi (2010).

4 Sobre esta idea, véase Mañalich (2011b).

5 Por todos, véase Marshall (2010).
} 
a sufragio. Para ello, en primer término, exponemos algunos antecedentes que se relacionan con la sentencia (2), el proceso que culminó con su dictación (3), y el contenido del fallo (4). Posteriormente, presentamos algunas reflexiones en torno a ciertos aspectos relevantes que deben tenerse en consideración respecto a la decisión de la Corte Suprema (5).

\section{ANTECEDENTES}

\section{a)}

LA AUDIENCIA DEL AÑO 2013

El año 2013, en el marco del desarrollo de una de las visitas semanales que por mandato legal los jueces de garantía deben realizar a los establecimientos penitenciarios en que se encuentran personas sometidas a prisión preventiva, un juez del 70 Juzgado de Garantía de Santiago, constató que algunos internos del Centro de Detención Preventiva Santiago Uno no podían ejercer su legítimo derecho a sufragio. Ante esto, ordenó el desarrollo de una audiencia para escuchar las explicaciones de diversos actores institucionales a fin de determinar las razones que explicaban esta situación. A dicha instancia asistieron representantes del Ministerio Público, la Defensoría Penal Pública, el Instituto Nacional de Derechos Humanos (en adelante INDH), Gendarmería de Chile y el Servel. En la audiencia, los tres primeros órganos indicaron que en el derecho chileno no existen normas que obsten a que las personas sometidas a prisión preventiva ejerzan su derecho a sufragio. Por su parte, Gendarmería señaló que no tenía inconvenientes en que se constituyeran mesas de votación en los recintos penales siempre que ello no afectara la seguridad de los mismos ni la integridad de los reclusos. El Servel fue el único órgano que manifestó reparos a esta posibilidad. A su juicio, carecía de facultades legales y administrativas para concretar la instalación de urnas. No obstante esto último, el juez ordenó al Servel implementar locales electorales en la mencionada unidad penal ${ }^{6}$. Sin embargo, la resolución no produjo efecto alguno. El acta de la visita que dio paso a la audiencia y la resolución dictada en ella fueron remitidas a la Corte de Apelaciones de Santiago. Producto de una queja interpuesta por el Consejo de Defensa del Estado en representación del Servel, el pleno de la Corte dejó sin efecto la medida, y determinó que el juez se había excedido en el ejercicio de sus atribuciones, infracción por la que abrió un sumario en su contra ${ }^{7}$.

\section{b) EL INDH y SU PREOCUPACIÓN POR EL DERECHO A SUFRAGIO DE LAS PERSONAS} PRIVADAS DE LIBERTAD

El ejercicio del derecho a sufragio de las personas privadas de libertad no fue una preocupación exclusiva del magistrado del $7^{\circ}$ Juzgado de Garantía. En los últimos años, el INDH ha sido uno de los órganos que mayor preocupación ha mostrado en el país por este tema. En diferentes informes el INDH ha relevado las consecuencias que se derivan de la situación que se presenta en el país a este respecto. En su "Informe Anual 2012", la institución indicó que la suspensión del derecho a sufragio que establece el artículo $16 \mathrm{n}^{\circ}$ 2 de la Constitución resulta contraria a la presunción de inocencia, pues implica establecer

\footnotetext{
6 Una breve descripción del evento del año 2013 puede encontrarse en MARShall (2016).

Instituto Nacional de Derechos Humanos (2013) p. 50.
} 
una sanción sin que se haya probado la responsabilidad penal de una persona. Por esto, recomendó al Estado adoptar las medidas indispensables para que las personas en prisión preventiva, así como aquellas imputadas que no se vieran afectadas por la restricción constitucional, pudieran ejercer su derecho a sufragio en los establecimientos penitenciarios ${ }^{8}$. En el "Informe Anual 2013" se abordó este problema a partir de la audiencia realizada por el juez del $7^{\circ}$ Juzgado de Garantía. El INDH recalcó que la imposibilidad fáctica de que las personas privadas de libertad legítimamente habilitadas puedan ejercer su derecho a sufragio constituye una vulneración general, automática e indiscriminada de este derecho. Para el organismo, esto implica entender, equivocadamente, que la privación de libertad inherentemente conlleva una restricción de derechos fundamentales diferentes a la libertad ambulatoria'. Además, y dadas las alegaciones del Servel en la misma audiencia, el INDH sostuvo que esta situación se debería a una interpretación restrictiva de la normativa electoral por parte del primer organismo ${ }^{10}$. Por último, en su "Informe Anual 2014", la institución reiteró estas ideas en un análisis específico de los problemas que presenta la regulación constitucional del ejercicio del derecho a sufragio para diversos grupos vulnerables en el país $^{11}$. Como explicaremos, estos argumentos encontraron su expresión en la estrategia judicial que emprendió el INDH el año 2016 con el fin de que las personas privadas de libertad lograran ejercer su derecho a sufragio.

\section{c) LA AUDIENCIA DEL AÑo 2016}

De manera similar a lo sucedido el año 2013, durante el año 2016, en el desarrollo de una visita al Centro de Detención Preventiva Santiago Uno, veintidós personas sometidas a prisión preventiva solicitaron a un magistrado del $7^{\circ}$ Juzgado de Garantía de Santiago poder ejercer su derecho a sufragio en las elecciones municipales. A partir de dicha petición, el juez citó a una audiencia a la que asistieron representantes de la Defensoría Penal Pública, del Ministerio Público, de Gendarmería de Chile, del INDH, de la Fundación Probono, de la Asociación Libertades Públicas, así como la abogada particular de un interno. Esta vez no se presentó el Servel. Todos los intervinientes reiteraron sus consideraciones en torno a la necesidad de implementar mecanismos que permitieran materializar el derecho a sufragio de las personas sujetas a prisión preventiva. Gendarmería volvió a expresar las mismas apreciaciones que en el caso anterior. Ante esto, el juez nuevamente ordenó al Servel arbitrar todos los medios necesarios para que tanto los internos que realizaron la solicitud, como aquellos que se encontraran en el territorio jurisdiccional del tribunal, pudieran ejercer su derecho a sufragio. La resolución del tribunal se basó, principalmente, en diversas disposiciones de tratados de derechos humanos; también incluyó referencias el "Informe Anual 2012" del INDH ${ }^{12}$, un fallo de la Corte Interamericana de Derechos Hu-

\footnotetext{
8 Instituto Nacional de Derechos Humanos (2012) p. 146.

9 Instituto Nacional de Derechos Humanos (2013) p. 50. Sobre esta idea, véase también Lazarus (2006).

10 Instituto Nacional de Derechos Humanos (2013) p. 50.

11 Instituto Nacional de Derechos Humanos (2014) pp. 26-27.

12 La resolución contiene la siguiente cita de dicho informe: "resulta contraria a la presunción de inocencia la suspensión del derecho a sufragio que establece la CONSTITUCión en su art. $16 \mathrm{~N}^{\circ} 2$ para los casos de personas imputadas de delitos que merezcan pena aflictiva o que estén acusados de delito calificados como terroristas. La
} 
manos ${ }^{13}$ y otro de tribunales argentinos ${ }^{14}$. El tribunal afirmó que se presentaba un estado inconstitucional de cosas producto de una imposición del propio estado chileno sobre un grupo de ciudadanas y ciudadanos claramente definido. Para constatar el avance en la implementación de las medidas dictaminadas, se citó a una audiencia para el día 16 de octubre del año $2016^{15}$. Esta no llegó a concretarse. De manera idéntica al suceso del año 2013 y por las mismas razones, el pleno de la Corte de Apelaciones de Santiago decidió dejar sin efecto la resolución dictada por el magistrado del $7^{\circ}$ Juzgado de Garantía de Santiago e instruyó un nuevo sumario administrativo en contra del juez ${ }^{16}$.

\section{EL RECURSO}

En forma paralela a la acción judicial, en septiembre de 2016, el INDH ofició al Servel para que informara respecto a la forma en que se pretendía hacer efectivo el derecho a sufragio de las personas privadas de libertad habilitadas para ello. La respuesta del Servel nuevamente alegó la imposibilidad de dar una solución satisfactoria sin la intervención del legislador. El INDH realizó la misma consulta a Gendarmería de Chile, pero no recibió respuesta. Ante esta situación, la institución interpuso una serie de recursos de protección en ocho Cortes de Apelaciones del país a favor de diversas personas privadas de libertad legitimadas para ejercer su derecho a sufragio. El organismo justificó su acción sobre la base de que tanto la contestación del Servel como la falta de respuesta de Gendarmería constituyeron un acto ilegal y arbitrario que afectó la posibilidad de que las personas privadas de libertad pudieran ejercer su derecho a sufragio. En lo que sigue explicamos el modo en que el INDH articuló su argumentación.

\section{a) El ARGUMENTO GENERAL DEL INDH}

La institución realizó una exposición sobre la importancia que poseen la ciudadanía y el derecho a sufragio en una democracia. Dado que la participación social y política constituye un pilar elemental para la configuración de un Estado democrático, sostuvo que el derecho a sufragio resulta esencial para su desarrollo y consolidación. En este contexto, la

pena es el resultado de un proceso Jurisdiccional que, cumpliendo las debidas garantías procesales, ha concluido la existencia de una responsabilidad penal de una persona. Consecuencia de lo anterior, es que el Estado debe adoptar las medidas pertinentes para que las personas en prisión preventiva voten en los establecimientos penitenciarios y para que aquellas imputadas, pero que no se encuentran en prisión preventiva, puedan votar en las mesas electorales que les correspondan". Véase $7^{\circ}$ JUZGADO DE GARANTIA DE SANTIAGO (2016) e InstituTO NaCiOnal de Derechos Humanos (2012) p. 146.

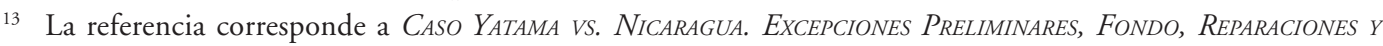
COSTAS (2005).

${ }^{14}$ Específicamente, se alude al fallo CENTRO LATINOAMERICANO DE DDHH/ Amparo-MENDOZA (2011). El tribunal sostiene que en dicho caso los jueces de la Cámara Nacional Electoral decidieron que la privación de sufragio a personas sometidas a prisión preventiva había sido declarada inconstitucional ya el año 2000 en el caso Mignone, reafirmado por la Corte Suprema de Argentina. Véase MIGNONE, S/HABEAS CORPUS (2002). Sobre la importancia e implicancias del caso Mignone, véase FiLIPPINI y Rossi (2012).

15 Véase $7^{\circ}$ JUZGADO DE GARANTÍ DE SANTIAGO (2016).

16 Véase Ahora noticias (2016a). 
Constitución limita el derecho a sufragio de las personas privadas de libertad. Sin embargo, señaló el organismo, en diversas elecciones previas se constató que ni el Servel ni Gendarmería de Chile implementaron mecanismos para garantizar que los reclusos habilitados pudieran votar. De acuerdo al INDH, esta situación implicaba una omisión ilegal y discriminatoria que vulnera la igualdad ante la ley y la libertad de expresión, garantías establecidas en el artículo $19 \mathrm{n}^{\circ} 2$ y n$^{\circ} 12$, respectivamente. Además, el organismo recurrió a diversos preceptos de instrumentos internacionales para reforzar su posición ${ }^{17}$.

\section{b) DERECHOS VULNERADOS}

En relación al derecho a la igualdad ante la ley, el INDH señaló que la imposibilidad de que las personas privadas de libertad puedan ejercer su derecho a sufragio las posiciona en un espacio de desigualdad estructural y arbitraria en comparación a los ciudadanos libres. Sobre la base de las normas del derecho internacional de los derechos humanos que consagran la prohibición de discriminación arbitraria y la garantía de igualdad frente a la ley (por ejemplo, el artículo 1 de la Declaración Universal de Derechos Humanos de 1948, o los artículos 2, 3, y 26 del Pacto Internacional de Derechos Civiles y Políticos de 1966), la institución indicó que la igualdad ante la ley constituye un derecho que las personas no pueden perder por el hecho de estar privadas de libertad, pues así lo exige la dignidad humana, en cuanto sustrato explicativo de todo derecho fundamental. A juicio del INDH, tanto el Servel como Gendarmería incurrieron en una vulneración directa de los derechos políticos de la población penal como resultado de la imposición de un esquema discriminatorio. De esto se desprendía una evidente amenaza para el ejercicio legítimo del derecho a la igualdad ante la ley de las internas y los internos.

Respecto a la libertad de emitir opinión que garantiza el artículo $19 \mathrm{n}^{\circ} 12$ de la Constitución, el INDH estimó que, si bien el contenido de este derecho admite diversas lecturas, nada obsta a que el sufragio pueda concebirse como un mecanismo para expresar opiniones políticas. Del mismo modo, argumentó que el derecho a sufragio puede entenderse como una manera de ejercer la libertad de expresión en un proceso electoral; por medio del voto se emite una opinión relacionada con las personas que se cree deberían ser elegidas para desempeñar determinados cargos. A la luz de la realidad que viven las personas privadas de libertad, el ejercicio del derecho a sufragio aparece como una medida inclusiva que contribuye a la profundización democrática y el desarrollo de procesos de participación política equitativos para todos los ciudadanos.

\section{c) ACCIÓN ILEGAL Y ARBITRARIA}

Para el INDH, el Servel incurrió en una actuación ilegal al no promover la implementación de medidas que aseguraran que las personas privadas de libertad ejercieran su derecho a sufragio. El artículo 67 de la Ley $\mathrm{N}^{\circ} 18.556$ de 1986 dispone en su letra i) que el "Consejo Directivo" del Servicio cuenta con la facultad de aprobar las políticas y medidas

\footnotetext{
17 Entre estos, destacan el artículo 21 de la Declaración Universal de Derechos Humanos de 1948; el artículo 25 del Pacto Internacional de Derechos Civiles y Políticos de 1966; y el artículo 23 de la Convención Americana sobre Derechos Humanos de 1969.
} 
para el acceso de las personas al ejercicio del sufragio, junto a lo cual, la letra h) de la misma disposición permite la dictación de normas e instrucciones para aplicar las disposiciones electorales que corresponda. Por otra parte, el inciso $2^{\circ}$ del artículo 50 del mismo cuerpo legal señala que "[e]l Servicio Electoral, por resolución fundada, podrá crear circunscripciones electorales cuando lo hagan aconsejable circunstancias tales como la cantidad de población, las dificultades de comunicación con la sede comunal o consular, las distancias excesivas o la existencia de diversos centros poblados de importancia”. El INDH expresó que, dada la configuración demográfica y la ubicación de los recintos penales, las hipótesis del artículo 50 resultaban aplicables y constituían una solución aceptable ante la vulneración de derechos descrita. El Servel, al desconocer esta argumentación, incurrió en una infracción legal que además resultaba arbitraria debido a que el oficio de respuesta a la consulta del INDH careció de una justificación razonable para negarse a la solicitud de crear locales electorales en recintos penitenciarios.

Por otra parte, el INDH indicó que la actuación de Gendarmería fue ilegal y arbitraria debido tanto a la falta de envío del registro de personas privadas de libertad domiciliadas en recintos penales al Servel, como a la carencia de acciones que tendieran a garantizar el ejercicio del derecho a sufragio del mismo grupo de personas. El artículo 21 bis de la Ley $\mathrm{N}^{\circ} 18.556$ de 1986 permite que cualquier persona pueda solicitar un cambio de domicilio electoral. Asimismo, los artículos 25 y 26 del mismo cuerpo normativo posibilitan que esta clase de actuaciones se realicen por medios no presenciales y que se celebren convenios entre instituciones públicas para materializarlas. A su vez, el artículo $4^{\circ}$ del Decreto Supremo № 518 de 1998, obliga a Gendarmería a desarrollar sus actividades con las garantías y dentro de los límites que establecen tanto la Constitución como los tratados internacionales ratificados por Chile ${ }^{18}$. Al interpretar estas normas de manera conjunta, el INDH consideró que la administración penitenciaria posee el deber de adoptar todas las medidas necesarias para que las personas privadas de libertad puedan ejercer su derecho a sufragio. Entre estas, la primera obligación legal que surge es la necesidad de adoptar una coordinación interinstitucional con el Servel para informar respecto a los domicilios de las personas privadas de libertad en unidades penales. La falta de acciones para concretar dicho objetivo llevó al INDH a calificar como ilegal la situación. Pero no solo eso. La omisión también resultaba arbitraria, dado que diversos instrumentos internacionales y parte de la normativa nacional reconocen que la pena privativa de libertad posee una finalidad de prevención especial positiva que se debe materializar en la reinserción de los condenados ${ }^{19}$. Bajo este marco, la

\footnotetext{
18 La disposición señala que "La actividad penitenciaria se desarrollará con las garantías y dentro de los límites establecidos por la Constitución Política de la República, los tratados internacionales ratificados por Chile y vigentes, las leyes y sus reglamentos y las sentencias judiciales. Los funcionarios que quebranten estos límites incurrirán en responsabilidad, de acuerdo con la legislación vigente". Art. 4º Decreto Supremo N 518 de 1998.

19 En cuanto a los instrumentos internacionales, el INDH acudió al artículo 5.6 de la ConVENCIÓn AMERICANA Sobre Derechos Humanos de 1969 que indica que "las penas privativas de la libertad tendrán como finalidad esencial la reforma y la readaptación social de los condenados"; al artículo 10 del Pacto Internacional De DeReChos Civiles y Políticos de 1966, que en su numeral 10 preceptúa que "el régimen penitenciario consistirá en un tratamiento cuya finalidad será la reforma y la readaptación social de los penados". También se refirió al número 87 de las Reglas Mínimas para el tratamiento de los reclusos (Reglas Mandela) de 2015. Respecto a la normativa interna, la institución argumentó esta idea sobre la base del artículo 1 del DeCreTo Ley $\mathrm{N}^{\circ} 2859$
} 
vigencia de los derechos políticos de la población penal sería esencial para alentar el respeto por las normas legales y cívicas, y reafirmaría un compromiso simbólico con la existencia del Estado de Derecho por parte de los condenados. Garantizar el derecho a sufragio de las personas privadas de libertad resultaría un elemento que contribuye a su reinserción.

\section{d) Solicitud}

Por las razones expuestas, el INDH solicitó a los órganos judiciales que: i) Se declarara ilegal y arbitraria la actuación del Servel respecto a la omisión de la instalación de mesas de votación en los recintos electorales; ii) se declarara ilegal y arbitraria la actuación de Gendarmería, en cuanto a la falta de envío de los registros en que figura el domicilio electoral de las personas privadas de libertad afectadas; iii) se declarara infringido el derecho constitucional de sufragio, el derecho a la igualdad ante la ley, y el derecho a emitir opinión de las personas privadas de libertad legítimamente habilitadas para votar; pero que por razones administrativas no podían ejercer estos derechos; iv) se instruyeran sumarios internos tanto en el Servel como en Gendarmería, a fin de determinar las responsabilidades administrativas que implicaron una afectación del derecho a la igualdad ante la ley, para así impedir la reproducción de esta situación; y v) se ordenara a ambos organismos adoptar todas las medidas de coordinación interinstitucional necesarias para restablecer el imperio del derecho y asegurar la tutela de los derechos fundamentales violados producto de las actuaciones ilegales y arbitrarias de Gendarmería y el Servel ${ }^{20}$.

\section{e) SOBRE LOS ARGUMENTOS DE LOS ÓRGANOS RECURRIDOS}

El Servel solicitó el rechazo de la acción. Señaló, en una posición idéntica a la que expresó en la audiencia del año 2013, que el sistema electoral del país se encuentra regulado por normas imperativas de derecho público. En particular, y sobre la base del artículo 50 de la la Ley $\mathrm{N}^{\circ} 18.556$ de 1986 , estimó que no resulta posible instalar locales de votación en las unidades penales. Para el Servel, si bien la norma permite crear circunscripciones electorales cuando circunstancias como la cantidad de población o la existencia de diversos centros poblados de importancia lo hagan necesario, un recinto penitenciario no puede considerarse por sí mismo como una circunscripción, ya que no constituye un determinado territorio físico, sino un bien inmueble que no se ajusta a ninguno de los criterios

de 1979 que establece que "Gendarmería de Chile [...] tiene por finalidad atender, vigilar y rehabilitar a las personas que por resolución de autoridades competentes fueren detenidas o privadas de libertad", el artículo 3 , letra e) del mismo cuerpo normativo que atribuye directamente a la administración penitenciaria la función de "[r]eadaptar a las personas privadas de libertad en orden a eliminar su peligrosidad y lograr su reintegración al grupo social”; y el artículo 1 del Decreto Supremo N 518 de 1998 que instituye como objetivo de la actividad penitenciaria "la atención, custodia y asistencia de detenidos, sujetos a prisión preventiva y condenados, así como la acción educativa necesaria para la reinserción social de los sentenciados a penas privativas de libertad o sustitutivas de ellas".

20 El texto de las acciones y los argumentos que referimos corresponden a las siguientes referencias: CHANG CONTRA SERVICIO ELECTORAL VIII REGIÓN Y GENDARMERÍa (2016a); INDH CON CABRERA (2016); INDH CON SERVICIO ELECTORAL IX REGIÓN Y OTROS (2016); INDH Y OTROS (2016); INDH CONTRA SERVICIO ELECTORAL Y GENDARMERÍA (2016); INDH CON SERVICIO ELECTORAL II REGIÓN Y GENDARMERÍ (2016); y MARELIC CON GENDARMERIA (2017a). 
que establece la norma para instalar locales de votación. Además, indicó que, de instalarse las mesas de sufragio en las prisiones, su resguardo estaría a cargo de Gendarmería de Chile, cuestión que contraviene el artículo 119 de la Ley $\mathrm{N}^{\circ} 18.700$ de 1988, que dispone que el resguardo de los locales de votación corresponde a las Fuerzas Armadas y a Carabineros de Chile. Por último, el Servel expuso que ambos argumentos hacían imposible cumplir con la solicitud del INDH; esto solo podría concretarse mediante una modificación legal.

La respuesta de Gendarmería fue más escueta. Se limitó a solicitar que se rechazara la acción, pues a su juicio no existía ilegalidad en sus actuaciones. Tanto las normas legales referidas por el Servel como cuestiones logísticas impedían materializar lo requerido por el INDH.

\section{f) FALLOS DE PRIMERA INSTANCIA}

Todas y cada una de las Cortes de Apelaciones denegaron las solicitudes del INDH en sus fallos, por considerar que los actos del Servel y Gendarmería no eran ni ilegales ni arbitrarios. Asimismo, consideraron que al momento de dictarse la sentencia ya se habían celebrado las elecciones, motivo por el que los recursos resultaban impertinentes. Prácticamente no se analizó el fondo de los argumentos jurídicos que sostuvo el INDH ${ }^{21}$.

Con todo, en el fallo de la Corte de Apelaciones de Temuco existió un voto disidente que examinó las consideraciones de la institución y estuvo por acoger el recurso, aunque solo en cuanto a la necesidad de declarar que el actuar de Gendarmería y el Servel fue ilegal y arbitrario. El ministro Alejandro Vera consideró que las personas privadas de libertad que figuraban en el recurso que le correspondió conocer, contaban de manera indubitada con su derecho a sufragio, dado que no podían encuadrarse dentro de alguno de los supuestos que establecen los artículos 16 y 17 de la Constitución. A juicio del ministro, del artículo $4^{\circ}$ de la Constitución, esto es, la consagración de Chile como un Estado democrático, deben desprenderse consecuencias para la extensión o vigencia de los derechos políticos en general, y del derecho a sufragio en particular. En atención al artículo $5^{\circ}$ de la Constitución, los órganos estatales poseen el deber de garantizar los derechos establecidos en la Constitución, las leyes, y los tratados internacionales, y de ello se deriva el deber de asegurar a las personas el derecho a participar con igualdad de oportunidades en la vida nacional, cuestión que cobra particular relevancia respecto a las elecciones democráticas, ya que estas constituyen una de las principales formas de ejercicio de la soberanía popular. De acuerdo a la opinión del ministro Vera, tanto Gendarmería como el Servel, en su carácter de órganos estatales, no cumplieron con el deber de respetar y promover los derechos garantizados por la Constitución y los tratados internacionales vigentes y ratificados por Chile. Agregó que ambas instituciones, a pesar de contar con los recursos materiales y legales para arbitrar los medios necesarios en orden a asegurar el pleno ejercicio de los derechos políticos de los internos, no lo habían hecho. Por tratarse de prerrogativas ciudadanas, toda limitación o restricción debía perseguir un fin estatal legítimo, cuestión que no se observaba en este caso. Por estas razones, ambos órganos habían incurrido en una afectación al derecho a la igualdad ante la ley de las personas privadas de libertad. Finalmente, el ministro argumentó que

21 A modo de ejemplo, véase MARELIC CON GENDARMERÍA (2017a). 
la limitación, e incluso discriminación en el ejercicio de los derechos políticos de la población penal en relación a los ciudadanos libres se debe a su posición, situación y condición de encierro, y no obedece a una pérdida legal o constitucional de su calidad de ciudadano. Por este cúmulo de razones, el magistrado Vera fue de la opinión de aceptar el recurso solo en cuanto a declarar que la conducta del Servel y Gendarmería era ilegal y arbitraria ${ }^{22}$.

\section{LA SENTENCIA DE LA CORTE SUPREMA}

El INDH apeló en contra de las decisiones de las Cortes de Apelaciones. El conocimiento y fallo de las impugnaciones correspondió a la Corte Suprema, órgano que decidió revertir el criterio de las Cortes inferiores, desechando así las consideraciones de los organismos públicos recurridos. El fallo de la apelación se produjo el día 2 de febrero de 2017. Correspondió a la Tercera Sala de la Corte Suprema integrada por los ministros Sergio Muñoz y Carlos Aránguiz; la ministra Rosa Egnem; la abogada integrante Leonor Etcheberry; y el abogado integrante Arturo Prado ${ }^{23}$. Solo existió un voto disidente por parte de la ministra Egnem, quien consideró que no existía medida urgente que adoptar, pues ya se habían realizado las elecciones que dieron paso a la interposición de la acción. Exponemos el razonamiento de la Corte en lo que sigue.

En primer lugar, el tribunal afirmó que el actuar de Gendarmería de Chile y el Servel resultó arbitrario, ya que contravino las normas internas y diversos instrumentos internacionales. Según la Corte, el Servel sí cuenta con la facultad de instalar locales de votación en los recintos penitenciarios. El artículo 52 de la Ley Orgánica Constitucional No 18.556 de 1986, no contiene una enumeración taxativa y excluyente de los lugares que pueden utilizarse como centros de votación. La instalación de urnas en las unidades penales permitiría que las personas privadas de libertad sufragaran, con independencia de si resulta o no necesario crear circunscripciones electorales para facilitar el proceso de sufragio; no habría impedimento normativo alguno ${ }^{24}$. La Corte agregó que la relación de derecho público entre los internos y el Estado consagrada en el artículo $2^{\circ}$ del "Reglamento de Estableci-

\footnotetext{
22 Para examinar la opinión del ministro Alejandro Vera, véase el voto disidente de la sentencia dictada en INDH CON SERVICIO ELECTORAL IX REGIÓN Y OTROS (2016).

23 Esta sentencia fue la primera en pronunciarse sobre el fondo. Anteriormente la Corte Suprema había declarado inadmisible el recurso presentado ante la Corte de Apelaciones de Antofagasta en LAGUES CON SERVICIO ELECTORAL II REGIÓN (2016). A su vez, el mismo día que se dictó la sentencia que comentamos, en conocimiento de la apelación interpuesta por el INDH en contra de la resolución que rechazó el recurso presentado ante la Corte de Apelaciones de Valparaíso, la Corte Suprema, de manera similar a lo que ocurrió en el caso de Arica, revirtió la decisión del tribunal inferior y reconoció la vigencia del derecho a sufragio de las personas privadas de libertad legitimadas para ello. Se trata del caso INDH Y OTROS (2017). Luego de estos pronunciamientos, la Corte Suprema confirmó las decisiones de las Cortes de Apelaciones de Temuco y Valdivia que rechazaron los recursos interpuestos por la institución de derechos humanos en las causas INDH CON CABRERA (2017); e INDH Y OTROS (2017). Por último, existen tres recursos de apelación que aún no han sido fallados por la Corte y se encuentran en estado de acuerdo, a la espera de la decisión del tribunal. Corresponden a las siguientes referencias: MARELIC CON GENDARMERIA (2017b); MARELIC CON SERVICIO ELECTORAL VII REGIÓN Y GENDARMERÍ (2017); y CHANG CONTRA SERVICIO ELECTORAL VIII REGIÓN Y GENDARMERÍA (2016b).

24 INDH CONTRA SERVICIO ELECTORAL Y GENDARMERÍA (2017), Considerandos $4^{\circ}$ y $5^{\circ}$.
} 
mientos Penitenciarios" 25 , junto a la necesidad de que el régimen penitenciario se ajuste a las normas que consagra la Constitución y los tratados internacionales, configuran el deber de Gendarmería en orden a velar activamente por el respeto de la condición de ciudadano de cualquier persona privada de libertad. En esta actividad, el órgano no solo debe atender a la normativa nacional, sino también a los instrumentos internacionales incorporados al ordenamiento jurídico interno ${ }^{26}$.

En segundo lugar, la Corte utilizó una serie de normas internacionales para justificar su decisión. Recurrió al artículo 25 del Pacto Internacional de Derechos Civiles y Políticos de 1966, que establece: "Todos los ciudadanos gozarán [...] sin restricciones indebidas, de los siguientes derechos y oportunidades: [...] b) Votar y ser elegidos en elecciones periódicas, auténticas, realizadas por sufragio universal e igual y por voto secreto que garantice la libre expresión de la voluntad de los electores”. Asimismo, la Corte acudió al artículo 23 de la Convención Americana sobre Derechos Humanos de 1969, que dispone: "1. Todos los ciudadanos deben gozar de los siguientes derechos y oportunidades: [...] b) de votar y ser elegidos en elecciones periódicas auténticas, realizadas por sufragio universal e igual y por voto secreto que garantice la libre expresión de la voluntad de los electores, y [...] 2. La ley puede reglamentar el ejercicio de los derechos y oportunidades a que se refiere el inciso anterior, exclusivamente por razones de edad, nacionalidad, residencia, idioma, instrucción, capacidad civil o mental, o condena, por juez competente, en proceso penal". Sobre la base de estas disposiciones la Corte argumentó que el derecho a sufragio constituye un derecho ciudadano cuyo ejercicio debe asegurar el Estado. Si bien este puede estar sujeto a eventuales restricciones, estas no pueden extenderse más allá de lo que señala la ley de cada país. Como señalábamos en la introducción, en Chile, las limitaciones al ejercicio del derecho a sufragio y la ciudadanía, respectivamente, se encuentran consagradas en los artículos 16 y 17 de la Constitución. Del texto de ambas disposiciones, la Corte coligió que, al no presentarse consideraciones que limiten el ejercicio del derecho a sufragio por la imposición de una medida cautelar -como la prisión preventiva-, o por una condena que no acarrea la pérdida del mismo derecho, el Estado debe garantizar su ejercicio ${ }^{27}$.

En tercer lugar, la Corte acudió a otras normas constitucionales. Argumentó que el artículo $1^{\circ}$ de la Constitución instituye el derecho de las personas a participar con igualdad de oportunidades en la vida nacional. Bajo esta idea, el ejercicio del derecho a sufragio constituye uno de los instrumentos de participación ciudadana más importante y afín con la democracia. Esto exige implementar todas las medidas necesarias para que las personas privadas de libertad que legal y constitucionalmente cuentan con derecho a sufragar puedan ejercerlo.

La Corte Suprema determinó que las actuaciones de Gendarmería de Chile y del Servel resultaron ilegales; la normativa interna y los tratados internacionales requieren que

\footnotetext{
25 El precepto dispone lo siguiente: "Será principio rector de dicha actividad el antecedente que el interno se encuentra en una relación de derecho público con el Estado, de manera que fuera de los derechos perdidos o limitados por su detención, prisión preventiva o condena, su condición jurídica es idéntica a la de los ciudadanos libres". Decreto Supremo No 518 de 1998.

26 INDH CONTRA SERVICIO ELECTORAL Y GENDARMERÍ DE ChILE (2017), Considerando 6 .

27 INDH contra SerVicio Electoral y Gendarmería de Chile (2017), Considerando $7^{\circ}$.
} 
el Estado vele por que las personas privadas de libertad legitimadas, puedan ejercer oportuna y adecuadamente su derecho a sufragio, sobre todo al considerar que la administración no puede vulnerar la garantía de igualdad de trato. Así, en definitiva, se acogió el recurso y ordenó, por una parte, que el Servel debe adoptar las medidas necesarias para que las personas privadas de libertad que no tienen suspendido su derecho a sufragio puedan ejercerlo; y por otra, que Gendarmería debe igualmente adoptar todas las medidas administrativas y de coordinación institucional que garanticen el derecho a sufragio de las mismas personas con una antelación que permita su ejercicio efectivo ${ }^{28}$.

\section{ANÁLISIS}

Dos tipos de observaciones pueden realizarse respecto a este importante fallo. Por un lado, constituye un avance relevante en la particular cuestión de la defensa del derecho a sufragio de las personas privadas de libertad. Por otro, da cuenta de que el poder judicial puede jugar un rol importante en la solución de la crisis de la institucionalidad carcelaria chilena, particularmente en lo que se refiere al respeto y tutela de los derechos de los internos.

\section{a) El DERECHO A SUFRAGIO DE LOS PRIVADOS DE LIBERTAD}

Hay cuatro aspectos relacionados con la protección del derecho a sufragio que vale la pena mencionar a propósito del fallo. El primer aspecto, es que la Corte Suprema posiciona a Chile en la línea de la tendencia transnacional de protección del derecho a sufragio de los privados de libertad impulsada por vía judicial. Debe observarse que la pérdida o suspensión de los derechos políticos de los privados de libertad no es una constante en el derecho comparado. Existen numerosos países donde este grupo ejerce estos derechos como cualquier otro ciudadano. Sin embargo, también existen países, como el nuestro, que establecen limitaciones al sufragio desde la prisión ${ }^{29}$. Son estas jurisdicciones las que han sido objeto de una tendencia transnacional que busca que los privados de libertad sean autorizados a sufragar. Los casos más importantes son el canadiense Sauvé v Canadá No. $2^{30}$, el sudafricano Minister of Home Affairs $v N_{C R}{ }^{31}$ y el caso británico tramitado ante la Corte Europea de Derechos Humanos, Hirst $v$ United Kingdom No. $2^{32}$. Todos ellos, inspirados en la protección del Estado de Derecho, los derechos fundamentales y el principio de democracia, han contribuido a consolidar un estándar transnacional en la materia que demanda que la privación del sufragio debe ser legalmente establecida, no puede ser aplicada anticipadamente, no puede tener efectos indeterminados o indefinidos y no puede afectar a personas condenadas por delitos menores ${ }^{33}$. El caso más importante del derecho comparado, por su parecido al caso chileno que comentamos, es el seminal August v Electoral Commis$\operatorname{sion}^{34}$, en Sudáfrica. En este caso, la ausencia de un sistema que implementara una forma de

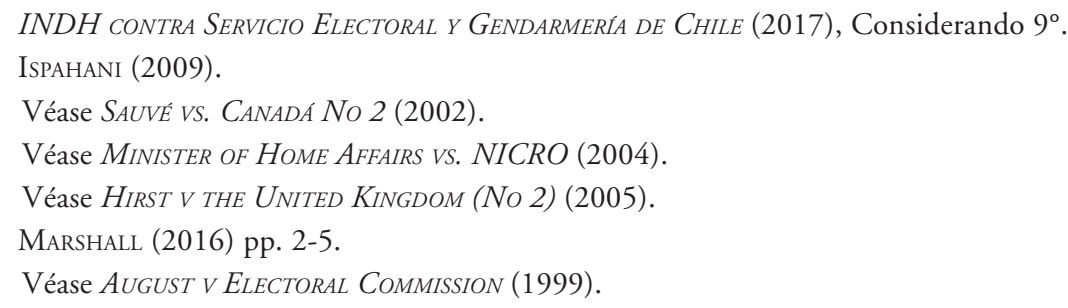


votación para los privados de libertad fue considerada como una omisión inconstitucional. El Tribunal Constitucional Sudafricano argumentó que el voto de cada ciudadano es una insignia de dignidad y de personalidad, además de que los reclusos retienen todos los derechos de los que no se les ha privado expresamente por el legislador. Por lo tanto, sostuvo, la Comisión Electoral Sudafricana, el equivalente a nuestro Servel, había violado la Constitución al no proteger el derecho al voto, cuya naturaleza impone obligaciones positivas tanto sobre el poder legislativo como sobre el ejecutivo. De esta manera, queda claro que el fallo de la Corte Suprema no es una iniciativa aislada, sino que por el contrario, forma parte de una tendencia transnacional sobre la protección de los derechos políticos de los privados de libertad ${ }^{35}$.

Un segundo aspecto destacado del fallo es la forma oblicua que la Corte aprueba para garantizar el ejercicio del derecho a sufragio mediante el uso del recurso de protección, consistente en la consideración de la igualdad como derecho vulnerado. De esta manera, se deja de lado una forma de concebir al sufragio como un derecho carente de garantía jurisdiccional que pueden utilizar los ciudadanos. Ello implica, por un lado, reivindicar el sufragio como un derecho fundamental tan importante como todos los demás establecidos en el artículo 19 de la Constitución. Por otro, da inicio a una fórmula en que la Corte Suprema está dispuesta a discutir problemas electorales que hasta ahora se encontraban fuera del ámbito de acción de la ciudadanía, lo que otorgaba al Servel una posición de cierta irresponsabilidad administrativa. Por ejemplo, y dado este fallo, no sería de extrañar que la Corte, de haber sido requerida, hubiera tomado una postura similar frente a los problemas de administración del padrón electoral por parte del Servel que impidieron sufragar a cientos de miles de ciudadanos que se encontraban mal inscritos en centros de votación fuera de sus comunas ${ }^{36}$.

El tercer aspecto interesante es el menosprecio con que la Corte aborda el argumento del Servel sobre la imposibilidad de implementación del sufragio dentro de la prisión. Mientras este último sostuvo que para implementar locales de votación en los recintos penitenciarios se requería una modificación legislativa, la Corte, al parecer, acepta el argumento del INDH sobre la plausibilidad de la instalación de mesas dentro de las unidades penales usando la facultad especial del Servel para crear circunscripciones, pese que su argumentación se centra en la legalidad de los centros penitenciarios como locales de votación. Si bien los argumentos de la Corte son correctos, y no existiría impedimento legal para la instalación de mesas en las cárceles, ni la Corte ni los recurrentes abordan la difícil cuestión de relacionar las mesas que allí se debieran instalar con las inscripciones electorales de los internos. Las personas privadas de libertad con derecho a sufragio no se encuentran inscritas necesariamente en la localidad de cada establecimiento penitenciario. Para ello tendrían que haber solicitado un cambio de domicilio ante el Servel. De esta manera, aun cuando fueran instaladas las mesas, solo los internos con residencia fijada en la circunscripción correspondiente con anterioridad podrían sufragar. Si bien en términos de principios los recurrentes y la Corte tienen razón en que los derechos electorales de los privados de libertad deben ser garantizados, la implementación de una solución fructífera para esta

\footnotetext{
35 Sobre esto puede consultarse, Ziegler (2011).

36 Para un resumen y consideraciones generales sobre este suceso, véase AHORA NOTICIAS (2016b).
} 
situación de vulneración requiere, y en esto sí tiene razón el Servel, de modificaciones más complejas que la mera instalación de mesas en los recintos penitenciarios. Esto requiere una modificación legal en la materia.

Finalmente, el fallo plantea dudas sobre las consecuencias prácticas que tiene para la efectiva protección del derecho a sufragio de las personas privadas de libertad. En la medida que las elecciones son eventos que transcurren cada cierto tiempo y en fechas precisas, sabemos con certeza que el resultado del recurso no derivó en que algún privado de libertad pudiera sufragar en la última elección municipal. De lo que no tenemos certeza es si este fallo significará que en las próximas elecciones presidenciales las cosas serán diferentes. Cualquiera sea el caso, esta sentencia, y las que seguramente seguirán, deben tomarse como una señal de alerta de parte de nuestras más altas autoridades judiciales sobre las condiciones de exclusión social y política que afectan a todas aquellas personas privadas de libertad. Ante esa alerta, las autoridades políticas y administrativas deberían comprometerse para que la implementación de un régimen de votación respetuoso de la Constitución y de los tratados internacionales no se haga esperar y esté disponible para las próximas elecciones presidenciales y parlamentarias. Resulta necesario reiterar que el derecho a sufragio no es un privilegio que las autoridades administran a voluntad; se trata de un derecho fundamental esencial para el funcionamiento de un régimen democrático y, en este caso, de un derecho fundamental del cual todas las personas que se encuentran en el supuesto denunciado ante la Corte Suprema son titulares indiscutidas. La lucha por el sufragio de las personas privadas de libertad en Chile está librando sus primeras batallas, y ha encontrado en las sentencias de la Corte Suprema su primera victoria. Al igual que con otros grupos excluidos anteriormente, la lucha por su inclusión política se puede presumir difícil y paulatina. Puede ser el caso que cuando se demuestre, como fruto de esta victoria, que es perfectamente posible que las elecciones se lleven a cabo dentro de la prisión, se dé paso a una discusión en torno a las reglas excluyentes de la Constitución chilena en sus artículos 16 y 17. Ambas disposiciones requieren actualizarse a la luz de los principios democráticos más elementales, conforme a los cuales, todos los miembros de una comunidad tienen derecho a ser oídos en el proceso de decisión de normas colectivamente vinculantes. Su inclusión electoral permitirá empoderar a los privados de libertad de una forma en que tendrían más y mejores oportunidades para que su voz sea oída cuando el debate público aborde cuestiones que los atañen como grupo específico. Es importante que las personas privadas de libertad tengan derecho a participar en las decisiones generales que atañen a toda la comunidad, pero en su caso por una razón adicional: su situación es una en que su vida se ve sometida de una forma extrema al control de la administración del Estado, de modo que nadie está en una posición mejor para identificar los problemas que afectan a la institución carcelaria. Ello, evidentemente, no quiere decir que una prisión democrática sea una en que las personas internas puedan decidir acerca de sus propias condiciones de reclusión, pero sí implica la necesidad de que sean oídas por quienes pueden tomar esas decisiones.

\section{b) UNA MIRADA CRÍTICA AL APARATO JUDICIAL EN LAS CÁRCELES CHILENAS}

Esta decisión también puede encuadrarse en una paulatina modificación de la forma en que la Corte Suprema se vincula con el sistema penitenciario. Frente a una realidad carcelaria marcada por carencias institucionales extremas y la desprotección jurídica de los 
internos ante el poder de la administración, la Corte se ha erigido paulatinamente como un órgano que protege y releva el valor de los derechos de las personas privadas de libertad.

Las tasas de encarcelamiento ubican a Chile como el cuarto país de la OCDE que más utiliza la prisión ${ }^{37}$. El año 2015, 43.708 personas estaban recluidas en establecimientos penitenciarios en Chile; al año 2014 la tasa de encarcelamiento del país era de 247 reclusos por cada cien mil habitantes ${ }^{38}$. En las cárceles chilenas existen elevados índices de hacinamiento, precarias condiciones de higiene y salubridad y los internos sufren múltiples vejaciones por parte de la autoridad penitenciaria. Estos factores se aúnan para constituir a las prisiones en espacios en que la vigencia del derecho es, al menos, cuestionable. Además, y a diferencia de otros países de la región ${ }^{39}$, en Chile no existe una ley general de ejecución penitenciaria ni un órgano jurisdiccional especializado en la materia. Por estas razones, no resulta del todo erróneo señalar que en Chile la justicia está de alguna manera ausente en las cárceles.

Esta situación se ha visto exacerbada por la carencia de una institucionalidad judicial coherente en sede penitenciaria y se expresa en que los internos han debido recurrir a los mecanismos constitucionales de protección y amparo como principales medios para perseguir el resguardo de sus derechos. Ambos institutos se han presentado como mecanismos ad-hoc para plantear peticiones ante la autoridad judicial ${ }^{40}$. Las ventajas que presentan estos recursos radican en su expedita tramitación, la certeza de obtener una respuesta por parte de la judicatura y el que ambos son conocidos por los tribunales superiores de justicia. No obstante, sus desventajas exceden sus aspectos positivos. Los internos desconocen los procedimientos legales para hacerlos valer, requieren de una tramitación escrita -una gran cantidad de internos son analfabetos ${ }^{41}$ y no aseguran niveles mínimos de protección jurisdiccional. Sobre este último aspecto, la literatura ha remarcado el rol que han desempeñado los tribunales. Jörg Stippel destaca que en la tramitación de ambos recursos los entes judiciales por lo general dictan resoluciones carentes de fundamentos, privilegian las versiones de los hechos sostenidas por la autoridad administrativa por sobre la de los internos sin justificarlo, e impiden la intervención efectiva de los reclusos en estas instancias ${ }^{42}$.

Dado este panorama, este fallo constituye una excepción al modo en que tradicionalmente los tribunales superiores de justicia en Chile se han vinculado con la tutela de los derechos de la población penal a través del ejercicio de acciones constitucionales. Pero no se trata de un suceso aislado. En los últimos años, la Corte Suprema ha comenzado a

\footnotetext{
37 STATISTA (2017).

38 El punto más álgido de las tasas de prisionización en Chile se dio el año 2010. Dicho año existían 53.410 personas privadas de libertad en el país y la tasa de encarcelamiento era de 313 internos por cada cien mil habitantes. Al respecto, véase International Centre for Prison Studies (2017).

39 Véase Valenzuela (2005).

40 Véase Salinero (2007) pp. 59 y ss.

41 Uno de los últimos estudios en la materia, realizado por Fundación San Carlos de Maipo, revela que la tasa de analfabetismo en las unidades penales, alcanza un 7,3\%, superando la tasa de la población general en un 2,5\%. Además, un $86 \%$ de los internos tiene escolaridad formal incompleta. Al respecto, véase LA TerCERA (2015).

42 STippel (2006) pp. 213-218.
} 
adoptar decisiones en materias relacionadas con el mundo penitenciario que revelan una posición de reconocimiento respecto a los derechos de la población penal. Esto ocurrió, por ejemplo, a propósito de la polémica en torno al acceso de los internos al denominado beneficio de "rebaja de condena" entre los años 2014 y 2015 ${ }^{43}$, y el caso de Lorenza Cayuhán y su hija a fines del año $2016^{44}$. En todas estas situaciones, la Corte Suprema ha adoptado un rol tutelar sobre los derechos de los internos, y particularmente respecto a la protección de su derecho a la libertad personal y la seguridad individual.

A nuestro juicio, estos sucesos constituyen un avance en el modo en que la Corte concibe la relación jurídica entre el Estado y el interno. Clásicamente, este vínculo se ha etiquetado como una "relación especial de sujeción" ${ }^{45}$. En términos generales, esto implica posicionar al interno como un subordinado del Estado, de manera que la administración puede afectar sus derechos sin mayor justificación; no existen mayores obligaciones para la autoridad. Con el fin de superar los problemas que suponen las relaciones especiales de sujeción en el ámbito penitenciario, las legislaciones modernas han identificado la "posición de garante" del Estado respecto a la población penal. Esta clase de regulación reconoce la relación entre el interno y el Estado desde un matiz positivo que deviene en la necesidad de que los organismos estatales protejan los derechos de las personas privadas de libertad $^{46}$. El Estado se encuentra en una posición en que posee verdaderos deberes de cuidado y protección sobre la población penal. Justamente esta idea es la que pareciera subyacer al razonamiento de la Corte en el fallo que analizamos. Su importancia radica en que permite hacer frente a las ilegalidades en que incurre la administración en el ámbito carcelario desde una situación jurídica que remarca la existencia de obligaciones estatales en el resguardo de la población penal, y cuya infracción posibilita exigir la adopción de medidas concretas en pos de tutelar sus derechos. En esta tarea, la Corte Suprema ha demostrado ser un órgano capaz de hacer frente a las carencias de la institucionalidad penitenciaria chilena y su incidencia en la vulneración de los derechos de las personas privadas de libertad.

\footnotetext{
43 Para una síntesis de este tema, véase Arriagada y Rochow (2015) pp. 171-173.

44 Se trata de un caso en que Gendarmería de Chile obligó a la comunera mapuche Lorenza Cayuhán a vivir su proceso de parto atada a una camilla con un grillete. Producto de esta situación, se interpuso un recurso de amparo a favor de la reclusa que fue rechazado en primera instancia por la Corte de Apelaciones de Concepción. Posteriormente la defensa de Lorenza Cayuhán apeló esta decisión y la Corte Suprema acogió el recurso. A juicio de la Corte, este hecho constituyó una actuación discriminatoria, ilegal y arbitraria por parte de la administración penitenciaria, pues infringió una serie de instrumentos internacionales relacionados con los derechos de las mujeres privadas de libertad y las minorías indígenas, así como la seguridad individual y libertad personal de la comunera. Por estas razones, el tribunal ordenó a Gendarmería, entre otras cosas, cumplir con la normativa internacional en materia de respeto y cuidado hacia las mujeres privadas de libertad y revisar sus protocolos de actuación en cuestiones relativas al traslado de internas e internos a recintos hospitalarios externos. Para cumplir con esto, la Corte remarcó la necesidad de que la normativa interna de la institución se ajuste a los instrumentos internacionales relativos a mujeres privadas de libertad embarazadas o con hijos lactantes, y aquellas disposiciones que dicen relación con la erradicación de toda forma de violencia y discriminación en contra de la mujer. Para analizar la sentencia de la Corte, véase CAYUHÁN CONTRA GENDARMERIA DE CHILE (2016).

45 El punto de inflexión para la superación de esta noción en el ámbito penitenciario se desarrolló en Alemania a partir de una sentencia dictada el año 1972 por el Tribunal Constitucional Alemán. Sobre esta idea, véase MARDONES (2011) p. 4.

46 Arriagada y Silva (2014) p. 113.
} 
A pesar de lo anterior, aún resulta problemática la tendencia que demostraron las Cortes de Apelaciones en este caso. El rechazo generalizado de las acciones presentadas por el INDH expresa la subsistencia de un desinterés por ejercer una tutela judicial efectiva sobre los derechos de las personas privadas de libertad, y también evidencia que el posicionamiento de la Corte Suprema como un agente que tiende a resguardar los derechos de la población penal es un fenómeno que no se ha asentado en las Cortes inferiores. Es de esperar que este fallo sea un punto de inflexión a este respecto.

Por último, quisiéramos destacar que el reconocimiento del derecho a sufragio de las personas privadas de libertad constituye un impulso para desarrollar un debate democrático y abierto en torno a las condiciones carcelarias del país y la necesidad de concebir a la población penal como miembros de la comunidad política, tal como exige un derecho penal de ciudadanos ${ }^{47}$.

\section{BIBLIOGRAFÍA CITADA}

Ahora noticias (2016a): "La Corte lo ordenó. Imputados en prisión preventiva no podrán votar en elecciones municipales". Disponible en: http://www.ahoranoticias.cl/noticias/ nacional/181530-corte-lo-ordeno-imputados-en-prision-preventiva-no-podran-votar-en-elecciones-municipales.html. Fecha de consulta: 14 de marzo de 2017.

Ahora nOticias (2016b): "Gobierno anuncia reunión con Servel para solucionar masivo error en padrón electoral”. Disponible en: http://www.ahoranoticias.cl/noticias/nacional/181723-gobierno-anuncia-reunion-con-servel-para-solucionar-masivo-error-en-padron-electoral.html. Fecha de consulta: 14 de marzo de 2017.

Arriagada, Isabel y Rochow, Diego (2015): "Privación de libertad en Chile: Desgobierno carcelario y afectación de derechos de la población penal", en Centro de Derechos Humanos Universidad Diego Portales (edit.), Informe Anual sobre Derechos Humanos en Chile 2015 (Santiago, Ediciones Universidad Diego Portales) pp. 161-207.

Arriagada, Isabel y Silva, Guillermo (2014): "La justicia ausente. El sistema penitenciario y el control judicial de la ejecución de la pena privativa de libertad en Chile", en AroCENA, Gustavo (edit.), El control judicial de la cárcel en América Latina (Buenos Aires, Ediar) pp. 101-166.

Balibar, Etienne (2004): We, The People of Europe? Reflections on Transnational Citizenship (Princeton, Princeton University Press).

Duff, Antony (2010): “A criminal law for citizens", Theoretical criminology, vol. 14, $\mathrm{N}^{\circ} 3$ : pp. 293-309.

FiLIPPINI, Leonardo y Rossi, Felicitas (2012): "Nuevos aportes sobre el reconocimiento del derecho a sufragio de las personas condenadas", Revista Jurídica de la Universidad de Palermo, Año 13, No 1: pp. 187-213.

GuZMÁn DÁlbora, José Luis (2008): La pena y la extinción de la responsabilidad penal (Buenos Aires, Editorial B de F).

47 Sobre esta idea, véase Duff (2010). 
Harcourt, Bernard (2014): "The invisibility of the prison in democratic theory: A problem of "virtual democracy", The Good Society, vol. 23, N 1: pp. 6-16.

Instituto Nacional de Derechos Humanos (2012): Informe Anual 2012. Situación de los Derechos Humanos en Chile (Santiago, Instituto Nacional de Derechos Humanos).

Instituto Nacional de Derechos Humanos (2013): Informe Anual 2013. Situación de los Derechos Humanos en Chile (Santiago, Instituto Nacional de Derechos Humanos).

Instituto Nacional de Derechos Humanos (2014): Informe Anual 2014. Situación de los Derechos Humanos en Chile (Santiago, Instituto Nacional de Derechos Humanos).

International Centre for Prison Studies (2017): "World Prison Brief data. Chile". Disponible en: http://www.prisonstudies.org/country/chile. Fecha de consulta: 12 de marzo de 2017.

ISPAHANI, Laleh (2009): "Voting rights and human rights: a comparative analysis of criminal disenfranchisement laws", en Ewald, Alec y RotTinghaus, Brandon (edits.), Criminal disenfranchisement in an international perspective (New York, CUP) pp. 25-58.

La Tercera (2015): “47\% de la población penal inicia su carrera delictual a los 13 años.” Disponible en: http://www.latercera.com/noticia/nacional/2015/07/680-637539-9el-47--de-la-poblacion-penal-inicia-su-carrera-delictual-a-los-13-anos.shtml. Fecha de consulta: 1 de abril de 2016.

Lazarus, Liona (2006): “Conceptions of liberty deprivation”, Modern Law Review, vol. 69: pp. $738-44$.

Mañalich, Juan Pablo (2011a): "Pena y ciudadanía”, en KindhäUser, Urs y Mañalich, Juan Pablo (edits.), Pena y Culpabilidad en el Estado democrático de Derecho (Buenos Aires, Editorial B de F) pp. 116-146.

Mańalich, Juan Pablo (2011b): "El derecho penitenciario entre la ciudadanía y los derechos humanos", Revista de Criminologia e Ciências Penitenciárias, vol. 1 NN$^{\circ}$ 1: pp. 1-30.

Mardones, Fernando (2011): La doctrina de las relaciones de sujeción especial en la jurisprudencia. Documento de Trabajo N 1/2011 (Santiago, Defensoría Penal Pública).

Marshall, Pablo (2010): "La pena y la ciudadanía: problemas constitucionales", en Cazor, Kamel y SalaS, Carolina (coords.), Estudios Constitucionales (Santiago, Librotecnia) pp. 249-270.

Marshall, Pablo (2013): "La persecución penal como exclusión política”, en MuÑoz, Fernando (edit.), Derecho, Igualdad e Inclusión (Santiago, LOM) pp. 69-91.

Marshall, Pablo (2016): "El derecho a sufragio de los privados de libertad en perspectiva comparada", Libertades Públicas/Colección Breviarios, $\mathrm{N}^{\circ}$ 1: pp. 1-17.

Salinero, Alicia (2007): Los permisos de salida en la legislación chilena. Informe en Derecho N $\mathrm{N}^{\circ}$ /2007 (Santiago, Defensoría Penal Pública).

STATista (2017): "Incarceration rates in OECD as of 2017". Disponible en: http://www. statista.com/statistics/300986/incarceration-rates-in-oecd-countries/. Fecha de consulta: 12 de marzo de 2017.

STIPpel, Jörg (2006): Las cárceles y la búsqueda de una política criminal para Chile (Santiago, LOM).

TAmbaKaKI, Paulina (2010): Human rights, or citizenship? (New York, CRC Press). 
VAlenzuela, Jonatan (2005): "Estado actual de la reforma al sistema penitenciario en Chile", Revista de Estudios de la Justicia, N 6: pp. 191-209.

ZIEGLER, Reuven (2011): "Legal outlier, again? U. S. felon suffrage: comparative and international human rights perspectives", Boston University International Law Journal, vol. 29: pp. 197-238.

\section{NORMAS CITADAS}

Constitución Política de la República.

Convención Americana sobre Derechos Humanos (22/11/1969).

Declaración Universal de Derechos Humanos (10/12/1948).

Decreto Ley No 2859 (15/9/1979), Fija Ley Orgánica de Gendarmería de Chile.

Decreto Supremo No 518 (21/8/1998), Aprueba "Reglamento de Establecimientos Penitenciarios".

LEY N 18.556 (1/10/1986), Ley Orgánica Constitucional sobre Sistema de Inscripciones Electorales y Servicio Electoral.

LEY N 18.700 (6/5/1988), Ley Orgánica Constitucional sobre votaciones populares y escrutinios.

Pacto Internacional de Derechos Civiles y Políticos (16/12/1966).

Reglas Mínimas para el tratamiento de los reclusos (Reglas Mandela) (17/12/2015).

\section{JURISPRUDENCIA CITADA}

$7^{\circ}$ JuzGado de Garantía de SANTIAGo (2016): $7^{\circ}$ Juzgado de Garantía de Santiago 30 de septiembre de 2016 (antecedentes administrativos rol 437-2016). Disponible en: http:// www.latercera.com/noticia/juez-ordena-a-servel-habilitar-mesas-para-que-imputadosvoten-en-las-carceles/. Fecha de consulta: 14 de marzo de 2016.

August v Electoral Commission (CCT8/99) [1999] ZACC 3. Disponible en: http://www. saflii.org/za/cases/ZACC/1999/3.html. Fecha de consulta: 1 de agosto de 2017.

Carolina Chang Rojas en Rep. de Instituto Nacional de Derechos Humanos contra Servicio Electoral Región del Biobío y Gendarmería de Chile (2016a): Corte de Apelaciones de Concepción 27 de octubre de 2016 (sentencia recurso de protección), Rol 19812-2016. Disponible en: http://corte.poderjudicial.cl/SITCORTEPORWEB/ DownloadFile.do?TIP_Documento=3\&TIP_Archivo=1\&COD_Opcion=1\&COD_ Corte $=46 \&$ CRR_IdTramite $=16513803 \&$ CRR_IdDocumento $=14899379$. Fecha de consulta: 1 de agosto de 2017.

Carolina Chang Rojas en Rep. de Instituto NaCional de Derechos Humanos contra SeRvicio Electoral Región del BiobÍo y Gendarmería de Chile (2016b): Corte Suprema 27 de diciembre de 2016 (apelación a recurso de protección), Rol 87876-2016. Disponible en: http://suprema.poderjudicial.cl/SITSUPPORWEB/DownloadFile.do?TIP_Documento=3\&TIP_Archivo=3\&COD_Opcion $=1 \&$ COD_Corte $=1 \&$ CRR_IdTra mite $=2797955 \&$ CRR_IdDocumento=2315523\&Cod_Descarga $=11$. Fecha de consulta: 1 de agosto de 2017. 
Caso Yatama vs. Nicaragua. Excepciones Preliminares, Fondo, Reparaciones y Costas (2005): Sentencia de 23 de junio de 2005. Serie C N 127. Disponible en: http://www. corteidh.or.cr/docs/casos/articulos/seriec_127_esp.pdf. Fecha de consulta: 1 de agosto de 2017.

Centro Latinoamericano de DDHH/ Amparo-Mendoza (2011): Cámara Nacional Electoral de la Nación Argentina 23 de septiembre de 2011. Fallo No 4692/2011. Disponible en: https:/www.pjn.gov.ar/jurisprudencia2/resultado.php. Fecha de consulta: 20 de agosto de 2017.

HIRST V THE UNITED KINGDOM (No 2) [2005] ECHR 681. Disponible en: www.ajd.org.br/ download.php\%3FendArquivo\%3Ddocumento/84_Corte_Europeia_-_Caso_Hirst.pd$\mathrm{f}+\& \mathrm{~cd}=4 \& \mathrm{hl}=\mathrm{es} \& \mathrm{ct}=\mathrm{clnk} \& \mathrm{gl}=\mathrm{cl}$. Fecha de consulta: 20 de agosto de 2017.

INDH CON CABRERA (2016): Corte de Apelaciones de Valdivia 10 de noviembre de 2016 (sentencia recurso de protección), Rol 933-2016. Disponible en: http://corte.poderjudicial.cl/SITCORTEPORWEB/DownloadFile.do?TIP_Documento=3\&TIP_Archivo=3\&COD_Opcion=1\&COD_Corte=55\&CRR_IdTramite=16599414\&CRR_IdDocumento=14982725. Fecha de consulta: 20 de agosto de 2017.

INDH CON CABRERA (2017): Corte Suprema 6 de marzo de 2017 (sentencia de fondo en apelación a recurso de protección), Rol 92816-2016. Disponible en: http://suprema. poderjudicial.cl/SITSUPPORWEB/DownloadFile.do?TIP_Documento=3\&TIP_Archivo=3\&COD_Opcion=1 \&COD_Corte=1\&CRR_IdTramite=2763742\&CRR_IdDocumento $=2281908 \&$ Cod_Descarga $=11$. Fecha de consulta: 20 de agosto de 2017 .

instituto Nacional de Derechos Humanos con Servicio Electoral iX Región y otros Corte de Apelaciones de Temuco 13 de diciembre de 2016 (sentencia recurso de protección), Rol 6143-2016. Disponible en: http://corte.poderjudicial.cl/SITCORTEPORWEB/DownloadFile.do?TIP_Documento=3\&TIP_Archivo=3\&COD_ Opcion=1\&COD_Corte=50\&CRR_IdTramite=16833214\&CRR_IdDocumento $=15207808$. Fecha de consulta: 20 de agosto de 2017.

instituto Nacional de Derechos Humanos con Servicio Electoral IX Región y otros (2017): Corte Suprema 16 de marzo de 2017 (sentencia de fondo en apelación a recurso de protección), Rol 41-2017. Disponible en: http://suprema.poderjudicial.cl/ SITSUPPORWEB/DownloadFile.do?TIP_Documento=3\&TIP_Archivo=3\&COD_ Opcion $=1 \&$ COD_Corte $=1 \&$ CRR_IdTramite=2786338\&CRR_IdDocumento $=2304251 \&$ Cod_Descarga $=11$. Fecha de consulta 20 de agosto de 2017.

Instituto Nacional de DeREChos Humanos Representante DaVID BaHAmondes Gonzales; BáRbara Inés Oyarzo Tobar; Carlos Manuel Valdés Cortés contra Servicio Electoral y GenDARMERÍA DE CHILE (2016). Corte de Apelaciones de Arica 24 de octubre de 2016 (resolución que declara inadmisible recurso de protección), Rol 662-2016. Disponible en: http:// corte.poderjudicial.cl/SITCORTEPORWEB/DownloadFile.do?TIP_Documento=3\&TIP_ Archivo=3\&COD_Opcion=1\&COD_Corte $=10 \& C R R \_I d T r a m i t e=16465451 \& C R R \_I d-$ Documento=14851761. Fecha de consulta: 1 de agosto de 2017.

Instituto Nacional de Derechos Humanos representante DaVid Bahamondes Gonzales; Bárbara Inés Oyarzo Tobar; Carlos Manuel Valdés Cortés contra Servicio ELECTORAL Y GendarmerÍa de ChILE (2017): Corte Suprema 2 de febrero de 2017 
(sentencia de fondo en apelación a recurso de protección), Rol 87743-2016. Disponible en: http://suprema.poderjudicial.cl/SITSUPPORWEB/DownloadFile. do?TIP_Documento=3\&TIP_Archivo=3\&COD_Opcion=1\&COD_Corte $=1 \& C R R \_$ IdTramite $=2735616 \& C R R \_I d D o c u m e n t o=2254438 \&$ Cod_Descarga $=11$. Fecha de consulta: 1 de agosto de 2017.

Instituto Nacional de Derechos Humanos y otros (2017): Corte Suprema 2 de febrero de 2017 (sentencia de fondo en apelación a recurso de protección), Rol 87748-2016. Disponible en: http://suprema.poderjudicial.cl/SITSUPPORWEB/DownloadFile. do?TIP_Documento=3\&TIP_Archivo=3\&COD_Opcion=1\&COD_Corte $=1 \&$ CRR_ IdTramite $=2735922 \&$ CRR_IdDocumento $=2254748 \&$ Cod_Descarga $=11$. Fecha de consulta: 1 de agosto de 2017.

instituto Nacional de Derechos Humanos, Servicio Electoral y otros (2016): Corte de Apelaciones de Valparaíso 21 de octubre de 2016 (sentencia recurso de protección), Rol 6970-2016. Disponible en: http://corte.poderjudicial.cl/SITCORTEPORWEB/ DownloadFile.do?TIP_Documento=3\&TIP_Archivo=1\&COD_Opcion=1\&COD_ Corte $=30 \& C R R \_I d T r a m i t e=16462830 \& C R R \_I d D o c u m e n t o=14848730$. Fecha de consulta: 1 de agosto de 2017.

Jefa Regional del Instituto Nacional de Derechos Humanos con Servicio Electoral II REG. y GENDARMERÍA DE CHILE (2016): Corte de Apelaciones de Antofagasta 6 de octubre de 2016 (sentencia recurso de protección), Rol 3625-2016. Disponible en: http://corte. poderjudicial.cl/SITCORTEPORWEB/DownloadFile.do?TIP_Documento=38TIP_ Archivo=3\&COD_Opcion $=1 \&$ COD_Corte $=15 \&$ CRR_IdTramite $=16338085 \&$ CRR_ IdDocumento=14730496. Fecha de consulta: 1 de agosto de 2017.

Lagues con SeRVICIO ELECTORAL II REGión (2016): Corte Suprema 21 de noviembre de 2016 (sentencia que declara inadmisible recurso de protección en conocimiento de apelación), Rol 82452-2016. Disponible en: http://suprema.poderjudicial.cl/SITSUPPORWEB/DownloadFile.do?TIP_Documento=3\&TIP_Archivo=3\&COD_ Opcion=1\&COD_Corte=1\&CRR_IdTramite=2595902\&CRR_IdDocumento $=2116701 \&$ Cod_Descarga $=11$. Fecha de consulta: 20 de agosto de 2017.

Lorenza Beatriz Cayuhán Lebul contra Gendarmería de Chile (2016): Corte Suprema 1 de septiembre de 2016 (sentencia que acoge recurso de protección), Rol 92795-2016. Disponible en: http://suprema.poderjudicial.cl/SITSUPPORWEB/DownloadFile. do?TIP_Documento=3\&TIP_Archivo=1\&COD_Opcion=1\&COD_Corte=1\&CRR_ IdTramite $=2617443 \&$ CRR_IdDocumento=2137929. Fecha de consulta: 28 de julio de 2017.

Marelic Rokov Branislav Ljubomir con Gendarmería de Chile (2017a): Corte de Apelaciones de Santiago 25 de enero de 2017 (apelación a recurso de protección), Rol 109602-2016. Disponible en: http://corte.poderjudicial.cl/SITCORTEPORWEB/ DownloadFile.do?TIP_Documento=3\&TIP_Archivo=3\&COD_Opcion $=1 \&$ COD_ Corte $=90 \&$ CRR_IdTramite $=17184176 \&$ CRR_IdDocumento $=15509541$. Fecha de consulta: 1 de agosto de 2017.

Marelic Rokov Branislav Ljubomir con Gendarmería de Chile (2017b): Corte Suprema 16 de febrero de 2017 (sentencia recurso de protección), Rol 4764-2017. 
Marshall, Pablo / Rochow, Diego —El sufragio de las personas privadas de libertad. Un análisis...

Disponible en: http://suprema.poderjudicial.cl/SITSUPPORWEB/DownloadFile. do?TIP_Documento=3\&TIP_Archivo=3\&COD_Opcion=1\&COD_Corte $=1 \& C R R \_$ IdTramite $=2886177 \&$ CRR_IdDocumento $=2402951 \&$ Cod_Descarga $=11$. Fecha de consulta: 20 de agosto de 2017.

Mignone, Emilio F. s/habeas corpus (2002): Corte Suprema de Argentina 9 de abril de 2002 (sentencia habeas corpus). Disponible en: http://www.ppn.gov.ar/sites/default/ files/CSJN.\%20Mignone\%209-4-02\%20fallo_0.pdf. Fecha de consulta: 25 de agosto de 2017.

Minister of Home Affairs vs. NICRO (CCT 03/04) [2004] ZACC 10. Disponible en: http://www.saflii.org/za/cases/ZACC/2004/10.html. Fecha de consulta: 25 de agosto de 2017.

SAUVÉ VS. CANADA No 2 (Chief Electoral Officer), [2002] 3 S.C.R. 519. Disponible en: http://portales.te.gob.mx/publicaciones/sites/default/files/archivos_libros/Sentencias\%20Relevantes\%20de\%20Cortes\%20Extranjeras\%20No.\%202.pdf. Fecha de consulta: 25 de agosto de 2017.

SR. Branislav Marelic Rokov en Rep. Del instituto Nacional de DDHH con Servicio ELECTORAL VII REGIÓN Y GENDARMERÍa DE ChILE (2017): Corte Suprema 8 de febrero de 2017 (apelación a recurso de protección), Rol 223-2017. Disponible en: http://suprema.poderjudicial.cl/SITSUPPORWEB/DownloadFile.do?TIP_Documento=3\&TIP_ Archivo=3\&COD_Opcion=1\&COD_Corte $=1 \&$ CRR_IdTramite $=2886101 \&$ CRR_IdDocumento=2402882\&Cod_Descarga=11. Fecha de consulta: 23 de agosto de 2017 . 